Lingua e Literatura, n 24, p. 11-22, 1998.

\title{
OCASO DA LITERATURA OU FALÊNCIA DA CRÍTICA?
}

\section{Benedito Nunes}

Os antigos gregos começaram, tardiamente, a ler, no sentido literário, os poemas homéricos que conheciam desde a infância, e que só foram comentados, de várias maneiras, a partir da época helenística. A crítica literária surgiria de tais escólios, portanto das glosas à literatura escrita, o que significa admitir que surgiu da prática da leitura dos textos, como decorrência da necessidade de compreendêlos e interpretá-los.

Daí por diante nāo haveria mais literatura sem crítica e sem leitura. As duas, critica e literatura, caminhariam juntas: a segunda vive por e para ser lida e a primeira só da leitura da outra pode viver. Nada mais trivial. Mas poderá ocorrer, como certos sinais pressagiam, que a literatura venha a perder, algum dia, sua ressonância critica, se não vier ela própria, também, a definhar, tornando-se, à falta de leitura, um simulacro de si mesma. Um simulacro igual àquele que da bela Helena de Tróia ficara, incólume e fiel a Menelau, resguardada no Egito, segundo nos conta Euripedes, enquanto a verdadeira teria ido, com Páris, incendiar Ílion, provocando a guerra da Ilíada.

Guanto mais a literatura for viva, quanto mais ela tiver importância num dado meio cultural, na proporção de seus leitores, mais florescerá a crítica literária em seus diversos gêneros. Pois onde a critica floresce, há várias "mansões" teóricas e metodológicas, como num reino dos céus de comentadores, analistas e intérpretes. 
Na Antigüidade e na Idade Média, o Gramático, o Retórico e até o Pedagogo, ocuparam as primeiras "mansões" da Crítica. No Renascimento, exerceu a Crítica o Humanista, esse fundador do cânone das letras clássicas. Cânone é palavra da religião que ingressou na literatura. Nos primeiros séculos do cristianismo, os abundantes escritos sobre a vida de Cristo foram separados em duas categorias. Evangelhos canônicos, como as quatro narrativas de São Lucas, São Marcos, São Mateus e São João, e evangelhos apócrifos, como os de Tomás, de Basilides e do pseudo Mateus, declarados falsos, condenados à execração e esquecidos até sua recuperação e publicaçāo em nossa época. Aqueles primeiros integram a parte central do cânone do Novo Testamento, composto de outros livros, todos reconhecidos como textos sagrados, fontes imutáveis da palavra divina.

Nas Letras, critérios poéticos, retóricos e estéticos identificam certos textos, em detrimento de outros, como literários; esse reconhecimento marca-lhes o caráter canônico, de onde decorre seu acatamento social num determinado periodo. Semelhantes aos textos religiosos, consagra-os a autoridade de uma tradição, mas, diferindo daqueles, vigem até serem substituidos por novos cânones. Consagrados, mas não sagrados e, às vezes, parecendo sêlo, os cânones literários remontam a principios, valores e modelos de que decorrem normas e regras.

Assim os cânones das Letras clássicas, que conformaram o "classicismo" erigiram, como modelos a imitar, com base na tradiçāo da Antigüidade e na autoridade da Poética de Aristóteles, da Epistola ad Pisones, de Horácio e do escrito de Longinus sobre o sublime, as obras valiosas desses normativos da literatura. O critico, mentor dessa tradição das Belas-Letras, pōe diante daqueles que as praticam o imperativo das regras decorrentes das normas, espelhando o perfil dos bons modelos épicos, líricos e trágicos do mundo greco-latino (Homero, Ésquilo, Sófocles, 
Euripedes, Virgilio, Cícero, Ovidio, sobretudo), expostos e comentados em continuidade à cadeia interpretativa que lá começou. O crítico era uma consciência feliz. Longe ainda estava dos juízos depreciativos - literato de segunda ordem, parasita, vampiro da literatura - com que irão infamá-lo os beletristas ou de que ele mesmo se acusará após o Renascimento.

Só a partir da transiçāo do século XVIII para o século XIX, por espelhamento na palavra "critica" então tornada preferencial - critica dos sentimentos, critica da experiência, critica da razão - foi que passou a haver uma critica literária com esta denominação - no momento em que, segundo parecer do Michel Foucault de Les Mots et Les Choses, a "literatura" propriamente dita teria surgido. Desde entāo a má consciência, nele hoje agravada, visitaria o crítico, em decorrência daqueles juízos depreciativos e que um diagnóstico psicanaliticamente primário pode elucidar. Dado que ele cobrava o respeito às regras, exprobando os que as transgrediam, logo funcionaria como um Superego autoritário, e, assim, como um “ inferior vindicativo” (Perrone-Moisés, 1978, p.17), condiçāo que recalcou e não aceitou.

O critico interiorizaria essa pecha como um sentimento de inferioridade quanto mais o solicitava, desde os fins do século XVIII, a estimulante difusāo iluminista: além de dicionários e enciclopédias, editavam-se periódicos, revistas ou jornais, nos quais se publicavam e comentavam romances para leitores mais numerosos que os de antanho, egressos tanto da antiga nobreza como da novel burguesia. Eram as duas grandes cabeças coletivas unidas, para o crítico, numa só entidade coletiva chamada de público, corpo da opiniāo que ele terá que honrar. O livro começava a reproduzir-se em maiores quantidades do que antes, com o crescimento desse corpo multitudinário, ao qual será endereçado. Mas quem lê sāo os individuos, com interesses distintos e pertencendo a diferentes classes sociais. Para eles é que o critico realmente fala, e por eles, como um 
direito que lhe assiste, posto em questāo pelo romantismo, quer ser escutado.

Já então contestado o cânone clássico, seus principios, invalidados como regras, sujeitar-se-āo ao juízo de gosto estético. Os românticos alemães, principalmente, contestam ao critico aquele direito, sob a alegação de que lhe faltaria competência para exercê-lo na base de julgamentos acerca da beleza artística, que nāo é extrínseca, como uma propriedade objetiva das obras, mas a elas intrínseca, como objeto de apreciação da parte de quem as contemplasse desinteressadamente, fruindo-as em função do prazer que proporcionam em consonância, portanto, com o sentimento do contemplador, em estado de atenção reflexiva.

Considerou-se o gosto estético a faculdade de discernimento do belo, equivalente a um ato de intuição espiritual, que iria ao encontro da imaginaçāo do artista no que ele produzia, da originalidade individual, afirmativa da liberdade de seu Eu - de seu gênio, essa disposição excepcional para criar (verbo novo do vocabulário artístico), como se compartilhasse das intençōes da Natureza e pudesse, conforme enunciaria Kant, dar regras à arte. Assim, nāo poderia o crítico julgar se não fosse um "autor em segunda potência" se não pudesse repetir o que o artista produzisse, se não fosse ele também poeta, um gênio imitando outro gênio. No entanto, Kant dizia que, no dominio do Belo, não poderia haver ciência, mas somente critica.

Em breve a critica se arrogaria ser porta-voz da opiniāo pública, julgando o mérito e o demérito dos textos, primeiramente à luz das intençōes do autor neles reveladas, depois, com o apoio das várias ciências em desenvolvimento no século XIX, pelo que documentam das disposiçōes psicológicas inerentes ao individuo, das exigências do momento histórico e das demandas da sociedade. A Psicologia, a História e a Sociologia foram chamadas a justificar os juizos criticos, de acordo com as leis naturais explicativas que se esperava que elas formulassem, e que também fun- 
damentariam, tal como acreditou Sainte-Beuve, o historiador de Port-Royal, em suas Causeries du Lundi (Conversaçōes da Segunda-feira) - artigos em série publicados em periódico de larga difusão - as apuraçōes do valor ou do desvalor dos escritos literários, aferidos segundo a concordância ou a discordância entre eles e as biografias dos artistas, que teriam a função de documentar. Mas essas conversaçōes semanais veiculavam uma atividade judicativa, que julgando a obra pela biografia do homem que a escrevera, pretendia triar o joio do trigo, separar, no terreno literário, as plantas viçosas das rasteiras e das daninhas.

Na verdade, conforme escreveu Proust, Sainte-Beuve conhecia bem os homens, mas conhecia mal os escritores, que procurava identificar nos documentos de suas vidas. Nem os encontraria como escritores se os procurasse em suas obras, porque nelas, onde o real perde para o estético, os escritores se outram, se inventam, se recriam. No século $\mathrm{XX}$, a crítica, além de sua modalidade difusa e reiterada de resposta às primeiras sugestões da obra imediatamente cantadas (impressionismo), visaria o elemento estético, como a especificidade a caracterizar o literário, ora tomado como organizaçāo poética de significaçāo autônoma e intransitiva (close-reading), ora à busca da forma significante da linguagem em suas operaçōes de construçāo interna (formalismo), ora na correspondência entre a forma e os significados sociais e históricos (crítica histórica e sociológica) - seja com apoio na Ciência da Linguagem (Estilística), seja com apoio na Fenomenologia (crítica fenomenológica), seja com o apoio na noção de estrutura lingüistica (crítica estruturalista).

Na segunda metade do século XX, todas essas correntes já eram largamente difundidas entre nós, mormente em artigos jornalísticos, à época um ordinário veículo da literatura e dos juizos críticos, utilizado desde a fase oitocentista de nossa critica, entre o romantismo que a fundou, com o seu componente nacionalista, e o naturalismo, 
que a vinculou ao meio social e ao então acreditado curso das leis históricas. Salvo a impressionística, tais correntes estavam todas representadas em 1961, no Segundo Congresso Brasileiro de Crítica e História Literária, reunido em Assis, por iniciativa da Faculdade de Filosofia e Letras dessa cidade paulista. Quem comparecesse a esse Congresso, marcado pela presença do concretismo como grupo de vanguarda, poderia testemunhar um momento alto, de pletora da literatura e de diversificado aumento qualitativo da critica.

Publicara-se, em 1956, Grande Sertão: Veredas, de Guimarães Rosa, e Duas Águas, de João Cabral de Melo Neto; em 1960, saira o livro de contos de Clarice Lispector, Laços de Familia. Continuavam renovadas as poesias de Carlos Drummond, Murilo Mendes, Jorge de Lima, Manuel Bandeira e Cecília Meireles. Explodira a vanguarda concretista, ascendiam novos poetas, como Mário Faustino, Ferreira Gullar e tantos outros. Tais eram os pontos em comum, as afinidades teóricas e os distintos niveis adotados na apreciação das obras, que as várias correntes criticas, representadas naquele Congresso - e veiculadas pelos jornais em seus suplementos literários - pareciam manter entre si, a despeito das diferenças metodológicas e doutrinárias que as separavam, um simpósio de complementação mútua e de reciproco enriquecimento.

Havia, por certo, desde a década de 40, uma crítica jornalística, a do reviewer, como dizia então Afrânio Coutinho, do resenhista, como dizemos hoje, mas também, pelo que ocorreu na década seguinte e depois, havia uma critica em estilo jornalístico, mais ágil e não menos apta do que a outra, e lado a lado, continuando uma linha já tradicional do jornalismo literário brasileiro, contávamos, dentro ou fora dos então famosos rodapés, com o artigo analitico, de exame e avaliaçāo de textos surgentes, como os de Alceu de Amoroso Lima (Tristão de Athayde), de Álvaro Lins, de Wilson Martins, Afrânio Coutinho e outros, em mais de um jornal, aos quais se adicionavam desde antes, nos órgāos da imprensa, os 
artigos, em forma ensaística, de Sérgio Buarque de Holanda, de Lúcia Miguel Pereira, ou, concomitante ou posteriormente aos primeiros autores citados, de Augusto Meyer Otto Maria Carpeaux, Antonio Candido, Adolfo Casaes Monteiro, Jorge de Sena, Franklin de Oliveira e Eurialo Canabrava, para falarmos somente daqueles criticos que mais assidua ou regularmente escreviam em periódicos, muitos deles sendo, também, professores universitários.

Do Diário de Notícias ao Correio da Manhã, do Jornal do Brasil ao Estado de Sāo Paulo, o jornal foi, pelo menos durante duas décadas, diante da restrita circulação de revistas, como veículo da critica literária, uma das princi-· pais caixas de ressonância pública da literatura em nosso país. Basta dizer, em confirmação disso, que a primeira recepção crítica das obras de Guimarães Rosa, de João Cabral e de Clarice Lispector se fez jornalisticamente.

Já em artigo publicado no Diário de Notícias, em 1948, Sérgio Buarque de Holanda previra o quanto as Faculdades de Filosofia, recém-fundadas, beneficiariam os estudos críticos, sobretudo na desconfiança que inspirassem "pelo autodidatismo e pelo personalismo exacerbado" A Teoria da Literatura, introduzida nos Cursos de Letras, não só traria esse beneficio. Também contribuiria para desrecalcar o crítico, ao mesmo tempo não permitindo, por força da dúvida que despertava no trato da coisa literária, devido à sua condição de teoria e não de ciência, que passasse do estado de má consciência ao estado de consciência plenamente satisfeita. Bem compreendida, a Teoria da Literatura daria um novo acesso, menos preconcebido, às Ciências Humanas e à Filosofia, à História e à Hermenêutica. Não há, em princípio, uma crítica universitária, por oposiçāo à crítica jornalística de boa qualidade, senão no sentido daquela que professores universitários assinam em jornais ou em livro, muitos dos quais, mais recentemente, se originariam de dissertações ou teses acadêmicas. 
Mas se, nos dias de hoje, os jornais não se fecharam de todo à critica, acolhendo-a quase que exclusivamente (valorize-se o quase como ressalva para as honrosas exceçōes) na forma de recensōes ou de informes editoriais, o certo é que se retrairam no papel de transmissores públicos dessa atividade. Altos seriam os custos da continuaçāo do exercício desse papel; diante do reduzido interesse do público pela crítica, apurado estatisticamente em "criteriosos inquéritos de opiniāo" nāo mais se justificaria, no presente, o investimento com que arcavam os beneméritos suplementos de outrora, publicando ensaios tão longos como os que se permitia estampar o Suplemento Dominical do Jornal do Brasil e concedendo ao colaborador, como fazia o Suplemento Literário de O Estado de São Paulo, o direito de enviar à redação a "matéria" que quisesse, dimensionada em quantia de laudas quase a seu arbitrio. Se essa pletora não pode se repetir, de quem é a culpa?

A culpa é do público, concluem os indices de opinião; a culpa é do mercado, clamam os sistemas empresariais de comunicação. Mas o desfalque, de que se ressente o antes próspero jornalismo literário, redunda em prejuízo para o leitor e para a literatura - sujeitos aos constritores padrōes informativos da midia, que os nivela a meios de rentabilidade para melhor consumo, convertido em nova mão da Providência econômica.

Nāo reivindicamos, apontando o predominante caráter mediático do jornalismo responsável pelo desfalque, conseqüente à retraçāo indicada, o retorno à situaçāo anterior, nem pretendemos "resgatar" o exílio jornalístico da crítica. Estamos, sim, assinalando o que talvez seja o sintoma da ascensāo de um novo tipo de mentalidade ou de "cultura" Poderá ser a "terceira cultura" (das duas, a humanística e a científica, tratou Sir J.P Snow), aquela correspondente ao avançado dominio planetário da técnica, em que tanto insistiu Heidegger - que é também o domínio do produtivel, do ciclo mercadológico - dentro do qual uma 
só corrente de demandas de consumo une, num único sistema empresarial de comunicação rentável, a fabricação do papel à produção do livro, da revista e do jornal, estes ao rádio, à televisão e ao computador. Pulsa, nesse domínio do produtivo e do rentável, que é também o da manipulação e da formalização do pensamento, tendendo a uniformizá-lo e a informatizá-lo, um ethos do lucro e do poder, à busca do fácil, do banal, do óbvio, com a sua mentalidade calculadora, imediatista, hedonistica, espetaculosa, um tanto megalômana, pouco a pouco descentrada da reflexão, do prazer contemplativo, das inquietaçōes intelectuais e filosóficas. Para tal mentalidade, a literatura, "ce métier de chambre" (ofício de câmara ou de quarto), como dizia Paul Valéry, vai se tornando estranha. Pois que a literatura como tal, principalmente a poesia, sabe ser lenta, tortuosa, às vezes difícil, inquisitiva, extraordinária, conflituosa, atordoante para o pensamento, com horizontes longinquos, e só degustável em calma reflexiva. Leyla Perrone Moisés resume, melhor do que eu, o efeito dessa mudança de atitudes: "Mais do que as mutaçōes tecnológicas elas mesmas, que não excluem a arte de escrever e de editar livros, podendo até renová-la, foram as mudanças de visão do mundo, de motivaçōes e de comportamento trazidas por essas novas técnicas que tornaram obsoleta a prática da literatura. O próprio modo de ser da pós-modernidade é avesso à concentração, ao isolamento e à paciência exigidos pela leitura."

O estado de simpósio metodológico e teórico da crítica literária, entrevisto em 1961, se desfez nos anos de governo ditatorial, que nos deram a "modernização do capital, de que a ditadura militar foi o braço armado" (Galvāo, 1998, p.57), concorridas bienais do livro e feiras de automóveis. Mas ainda nesse periodo, uma saudável crítica da crítica veio mostrar não sermos, como críticos, mais do que intérpretes, social e historicamente situados. Quando avaliamos as obras, nós as vemos sempre de uma certa 
perspectiva, que nos limita e nos ensina as viseiras de nossos juizos de valor. Isso é um excelente ganho da Hermenêutica e das Estéticas da recepção, como o é, também, o reconhecimento do caráter mutável dos cânones, o que já sabia o semioticista Mukarovski, quando os vinculou a condiçōes geracionais de idade, de profissão, de classe social e de nação. Mas passamos a "destruir" e a "construir" cânones, apressadamente e um tanto à vontade. Com essa atitude, desrespeitamos o tempo histórico; bloqueados num presente ocluso, sem passado, infringimos a Hermenêutica, com o seu justo apelo à tradição fecunda, e esquecemos que, no melhor sentido, "destruir" o tradicional é recuperar as suas raizes pretéritas, porventura ocultas no presente. Para que, entāo, serve a crítica?

Suponhamos, como George Steiner, que a critica, da qual estariamos saturados por um excesso de comentários, de análises e de interpretações, seja dispensável, e que dela nos liberemos para podermos fruir diretamente as obras literárias, em suas "reais presenças" Mas como reconhecer essas presenças reais, se, como professores de literatura, ensinamos mais a "destruir" os cânones do que a reconhecê-los sem veneração religiosa, e se muitos de nós se omitem ao dever principal, suporte da ética da literatura, de transmitir aos nossos estudantes o prazer da leitura dos textos: prazer que, adestrando reflexiva e criticamente a mente e o coração de quem o experimenta, prolonga-se em descoberta de nós mesmos e do mundo?

$\mathrm{E}$, no entanto, em nosso país, jamais se viu, como hoje, um tāo grande e diversificado movimento editorial: "livros, livros à mão cheia" fartíssimo material para leitores de toda ordem. Nossos clássicos saem em ediçōes baratas, muitas delas providas de generosos folhetos de questōes e respostas para o professor e o aluno, que interpretam didaticamente, em lugar deles, os textos literários. Nosso céu tem mais leitores, nossos livros mais amores. Nem tanto. Vide as verdes campinas literárias brasileiras 
(e os nem sempre cinzentos prados franceses), atulhados de montes cinco e compostelas, que não as de Luis Buñuel. "Uns tomam éter, outros cocaina"; mas muitos leitores tomam o entorpecente fabricado com sobras de hinduísmo ou budismo e raspas de espiritualismo cristão em calda de auto-ajuda. Podemos nós, criticos e professores de literatura, fazer mea culpa pela atual confusão, mesmo na França, entre literatura e auto-ajuda? ${ }^{1}$

Já nos envergonhamos de referir os grandes "mestres do passado", a prezar os "monumentos da literatura" Se continuar o recesso da leitura, Homero, Joyce e Guimarães Rosa deixarão de ser dentro em breve, "the companions we keep", companheiros de leitura e de vida. Suponhamos, enfim, que o triunfo da mentalidade antes retratada seja a derrota da literatura, convertida em simulacro, a leitura deslizando para o antiliterário, como entorpecente do espírito, e a crítica falida, com o seu público reduzido, sem condições de recepção fora do meio universitário. O que, então, fazer com a literatura, não com o simulacro, a relíssima, imediatista e utilitarista Helena, que teria ficado no Egito, mas com a sedutora, a mitopoética Helena, aquela que conflagrou Tróia, que não vive sem critica e morre sem leitura?

Belém,13 de julho de 1998.

(1)Ledo engano pensar que a "terceira cultura" nāo avançou na França, onde, segundo dados de 1978 (Noiret), 50\% dos instruídos cidadãos não costumam ler, percentual tendendo a $100 \%$ no caso da poesia. 
BIBLIOGRAFIA

FOUCAULT, M. Les Mots et les Choses. Paris, Gallimard, 1966.

GALVĀO, W Desconversa. Rio de Janeiro, Editora da UFRJ, 1998.

HOLANDA, S. B. "Missão e Profissão" in O Espirito e a Letra. Estudos de Crítica Literária II (1948/1959). São Paulo, Companhia das Letras, 1996.

MUKAROVSKY, J. "Função, Norma e Valor Estéticos como Fatos Sociais (1936)" In Escritos sobre Estética e Semiótica da Arte. Lisboa, Editorial Estampa, 1993.

NOIRET, G. "Crise(s) de la poésie, poésie de la crise" Esprit, jan. 1978.

PERRONE-MOISÉS, L. "A Crítica Literária Hoje", in Cânones e Contextos. Quinto Congresso da ABRALIC, Rio de Janeiro, 1997

. Texto, Crítica e Escritura. Sāo Paulo, Ática, 1978.

STEINER, G. Reélles présences. Paris, Gallimard, 1989. 